\title{
Inter-turn Short Circuit and Unbalanced Voltage Pattern Recognition for Three-Phase Induction Motors
}

\author{
Rodrigo López Cárdenas ${ }^{1}$, Luis Pastor Sánchez Fernández ${ }^{1}$, \\ Oleksiy Progrebnyak ${ }^{1}$, and Ángel Alberto Costa Montiel $^{2}$ \\ ${ }^{1}$ Center for Computing Research, National Polytechnic Institute. Mexico \\ ${ }^{2}$ CIPEL. Higher Polytechnical Institute "José Antonio Echeverría". Cuba \\ rodrigo@sagiatrio.cic.ipn.mx, \{1sanchez, olek\}@cic.ipn.mx, \\ aacmelectrica.cujae.edu.cu
}

\begin{abstract}
A novel diagnostic approach, by means pattern recognition, is proposed for the early detection of inter-turn short circuit on three-phase induction motor and unbalanced input voltage detection. The essential concept is that a minimum inter-turn short circuit at stator motor or unbalanced input voltage produces a slight variation that can be identified in current and rotor speed signals. To achieve this, an own motor mathematical model was created, and in order to generalize the diagnostic for a wide range of motor, is used a novel method to calculate motor parameters through data catalogue. Through this, motors of different power and poles number are emulated and, from these results, an original methodology to transform temporal response in patterns is created.
\end{abstract}

Keywords: diagnostic, induction motors, pattern, recognition, monitoring.

\section{Introduction}

Three-phase squirrel cage induction motors are essential components in most of today's manufacturing and production industries. Safety, reliability, efficiency and performance are some of the major concerns and needs for motor system applications [1] [2].

The goal of this research is create an original methodology to obtain patterns to recognize early inter-turn short circuit at stator induction motor principally, and in addition, detect unbalanced voltage in motors between ranges of $0.75 \mathrm{~kW}$ to $4 \mathrm{~kW}$. To achieve this, a novel mathematical model of squirrel cage induction motor was created that has important differences with common models. Mathematical induction models like [3] use construction motor parameters, that is, rotor and stator resistances, rotor, stator and mutual inductances. These kinds of parameters only are accessible to manufacturers or are extracted from theory literature. Simulate squirrel cage induction motors with these parameters implies to use the rotor resistance like a constant, assuming that squirrel cage maintains the same value during all start-up process, ignoring that rotor resistance vary with time as function of motor slip [4]. Although exist methods than can diagnose inter-turn short circuit [5], all of them use a physical motor to extract its parameters, and therefore, their methodology is difficult to 
generalize. This paper proposes a methodology to transform temporal motors response to patterns. An own mathematical model was created associated to novel computational algorithm that uses the rotor resistance variation and iron losses, as well as inter-turn short circuit information to emulate a real process operation. Therefore, is possible transform temporal response to patterns and recognize inter-turn short circuit in different intensities. The simulation algorithm's input are quite different, since the extraction data is trough data catalogue, leading to generalization to a wider range of motors.

\section{Mathematical Models}

Exists several methods to obtain motor parameters, some of them use analysis of magnetic field, others perform tests of steady state with/without load, others use frequency analysis transient identification response and finally, through data catalogue. The particular method to extract parameters is fully described in [4], where through data catalogue are extracted inductance and resistance constants and motor nominal values, these parameters are needed to emulate the motor with the mathematical model show below. It is important to note, that the following equations are been transformed from tri-phase to bi-phase system, abc - $\alpha \beta$, with the intention of simplifying mathematical calculations [6].

The stator voltage equations are:

$$
u_{s \alpha}=\frac{R_{s}}{L_{\sigma m}} \varphi_{s \alpha}-\frac{R_{s}}{L_{\sigma m}} \varphi_{\sigma \alpha}+\frac{d \varphi_{s \alpha}}{d t} ; \quad u_{s \beta}=\frac{R_{s}}{L_{\sigma m}} \varphi_{s \beta}-\frac{R_{s}}{L_{\sigma m}} \varphi_{\sigma \beta}+\frac{d \varphi_{s \beta}}{d t}
$$

Since the motor is a squirrel cage, the rotor voltage is zero:

$$
0=\frac{R_{r}}{L_{\sigma m}} \varphi_{s \alpha}-\frac{R_{r}}{L_{\sigma s}} \varphi_{\sigma \alpha}+\frac{d \varphi_{r \alpha}}{d t}+\frac{2}{P} \omega_{m} \varphi_{r \beta} ; \quad 0=\frac{R_{r}}{L_{\sigma m}} \varphi_{s \beta}-\frac{R_{r}}{L_{\sigma s}} \varphi_{\sigma \beta}+\frac{d \varphi_{r \beta}}{d t}+\frac{2}{P} \omega_{m} \varphi_{r \alpha}
$$

Where the coupling inductances are:

$$
L_{\sigma s}=\frac{L_{S} L_{R}-L_{M}^{2}}{L_{S}} ; \quad L_{\sigma r}=\frac{L_{S} L_{R}-L_{M}^{2}}{L_{R}} ; \quad L_{\sigma m}=\frac{L_{S} L_{R}-L_{M}^{2}}{L_{M}} ;
$$

The mechanical equation is:

$$
\frac{3}{2} \frac{P}{2}\left(\varphi_{s \alpha} i_{s \beta}-\varphi_{s \beta} i_{s \alpha}\right)=J \frac{2}{P} \frac{d \omega_{m}}{d t}+m_{m e c}\left(\omega_{m}\right)
$$

Where $i_{s \alpha}$ and $i_{s \beta}$ currents are:

$$
i_{s \alpha}=\frac{1}{L_{\sigma r}} \varphi_{s \alpha}-\frac{1}{L_{\sigma m}} \varphi_{r \alpha} ; \quad i_{s \beta}=\frac{1}{L_{\sigma}} \varphi_{s \beta}-\frac{1}{L_{\sigma m}} \varphi_{r \beta}
$$

In the above equations, $u_{s \alpha}$ and $u_{s \beta}$ are input transformed voltages; $R_{s}$ and $R_{r}$ are stator and rotor resistances; $L_{S}, L_{R}$ and $L_{M}$ are stator, rotor and mutual inductances; 


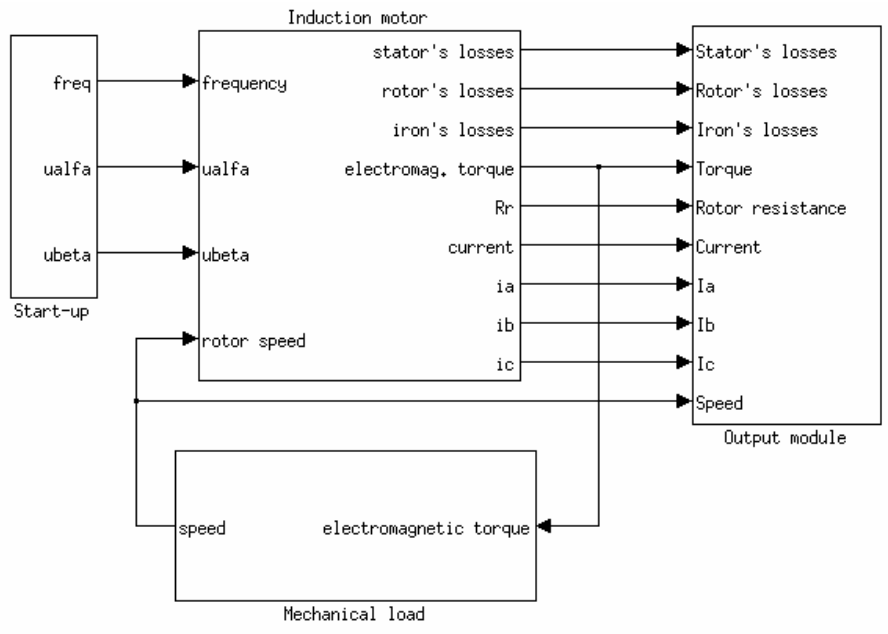

Fig. 1. Simulink implementation of computational algorithm

$i_{s \alpha}$ and $i_{s \beta}$ are transformed stator currents, $J$ is the total motor inertia, $m_{m e c}$ is the mechanical moment, $\omega_{m}$ is the motor angular speed, and $L_{\sigma s}, L_{\sigma r}$ and $L_{\sigma m}$ are coupling inductances. The associated computational algorithm was programming using Matlab Simulink, the Fig. 1 shows its block diagram.

\section{Methodology to Transform Temporal Response in Patterns}

The temporal responses consist in different conditions, that is, normal condition or without fail, unbalanced voltage with $5 \mathrm{~V}, 10 \mathrm{~V}, 20 \mathrm{~V}$ and $30 \mathrm{~V}$ of input voltage and, inter-turn stator short circuit with $5 \%, 10 \%, 20 \%$ and $30 \%$ of phase-a. The unbalanced voltage is done varying any input voltage in value cited above, while inter-turn short circuit suppose a diminution in stator resistance proportional to number of interturn short circuited. Then selecting phase-a because it matches with phase- $\alpha$, the stator resistance is:

$$
R_{s \alpha}=\left(1-e_{s c}\right) R_{s}
$$

Where $e_{s c}$ is the proportion of inter-turn short circuit. Then, stator voltage equitations are transformed to:

$$
u_{s \alpha}=\frac{R_{s \alpha}}{L_{\sigma m}} \varphi_{s \alpha}-\frac{R_{s \alpha}}{L_{O m}} \varphi_{\sigma \alpha}+\frac{d \varphi_{s \alpha}}{d t} ; \quad u_{s \beta}=\frac{R_{s}}{L_{\sigma m}} \varphi_{s \beta}-\frac{R_{s}}{L_{\sigma n}} \varphi_{\sigma \beta}+\frac{d \varphi_{s \beta}}{d t}
$$

With this mathematical background and using Matlab Simulink, different power and pole number motors were simulated and data were acquired for the situations cited above. 


\subsection{Pre-processed Signal}

The Fig. 2 presents an example of an induction motor with the following characteristics: nominal power $=1.5 \mathrm{~kW}$, line voltage $=230 \mathrm{~V}$, nominal current $=6.1 \mathrm{~A}$, frequency $=50 \mathrm{~Hz}$, poles $=4$ and nominal speed $=1410 \mathrm{rpm}$. The figure shows normal operation or operation without fail, $30 \%$ inter-turn short circuit and $30 \mathrm{~V}$ unbalanced voltage. We can see from figure the slight variation of speed curve with fail and without it. The current signal is a combination of the two transformed currents, $i_{s \alpha}$ and $i_{s \beta}$, it can be observed a current ripple and a noticeable displacement with respect normal condition. This behavior is also reported in [7].

Some authors as [8] perform a spectral analysis especially from signal current, but in this research we propose an alternative way to resolve this kind of fail in induction motors.
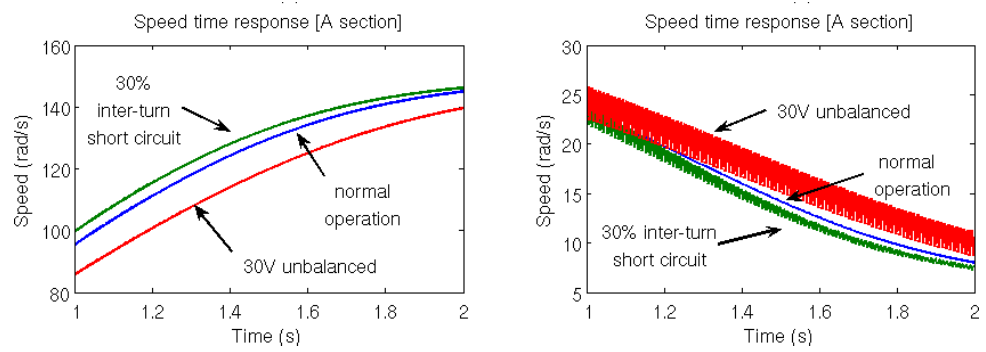

Fig. 2. Speed and current signals from 4 pole $1.5 \mathrm{~kW}$ induction motor

From merely visual inspection, we can see a direct relation between speed and current, this is the reason that our analysis is centered in the relationship between these two essential characteristic, creating patters that are "absolute" and "relative" to normal operations. The first step was constructed a data bank of motors with the conditions described above respect unbalanced voltage and inter-turn short circuit. In this paper, were elected motors between the range of $0.75 \mathrm{~kW}$ to $4 \mathrm{~kW}$; with $2,4,6$ and 8 poles and a line voltage of $230 \mathrm{~V}$ and $400 \mathrm{~V}$. To eliminate the current ripple was necessary decimating the signal with an eight-order lowpass Chebyshev Type I filter with a cutoff frequency of:

$$
F c=\frac{0.8 F_{2} / 2}{r}
$$

Where $F_{s}$ is the frequency sample and $r$ is the factor of decimating, in this case the factor is ten. The Fig. 3 shows the speed versus current for the same motor with normal condition and $30 \%$ of inter-turn short circuit, it also shows the original signal with ripple and the new signal yet filtered.

\subsection{Patterns Extraction}

The creation of these patterns considers only transient state and with all signals preprocessed, speed and currents, and each of them representing different conditions, the 

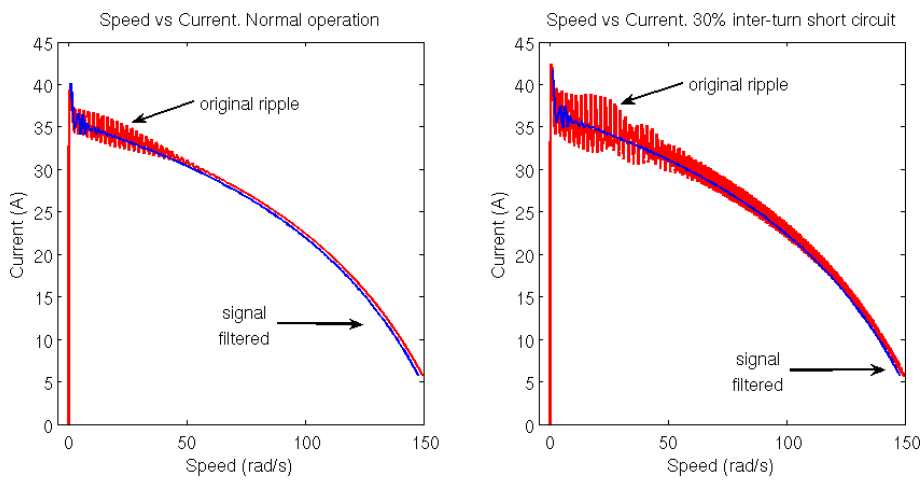

Fig. 3. Speed versus current. Original signal and filtered.

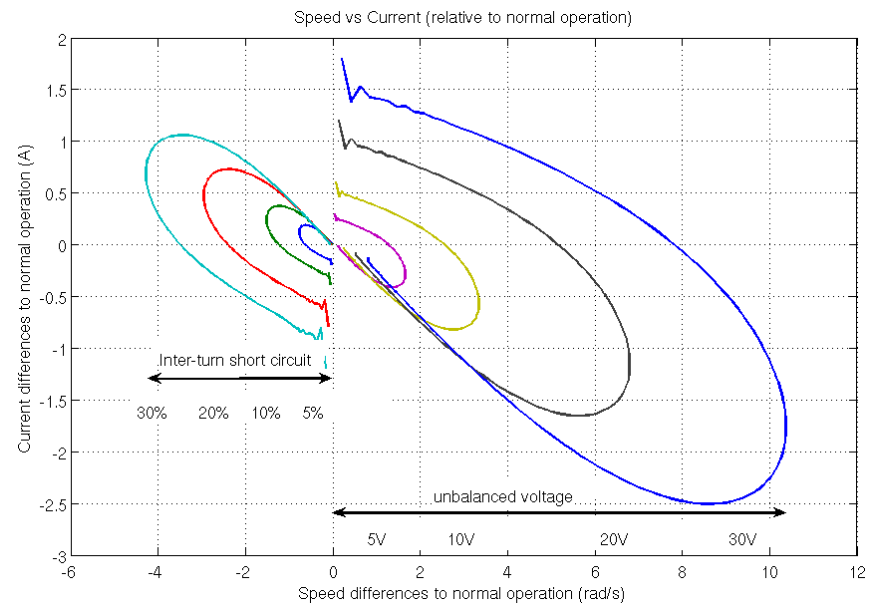

Fig. 4. Speed difference vs current different for same motor and different abnormal situations

next step was the extraction of certain peculiarities between normal condition and abnormal condition -inter-turn short circuit and unbalanced voltage- from which is possible extract important information, as shown in Fig. 4. That figure shows at $\mathrm{x}$-axis the relative differences between velocities and over y-axis relative differences between currents, all differences are normal condition with respect a potential fail. That figure shows the eight conditions considered in this paper, in noticeable the particular behavior for each condition: the inter-turn short circuit generates negative speed differences and positive current differences, while unbalanced voltage generates positive speed differences and negative current differences with greater magnitudes than interturn short circuit. This behavior remains constant for all motors considered regardless power and poles number. 


\subsubsection{Absolute Time Patterns (Characteristics)}

The Fig. 5 shows the way that these patterns were extracted. In the particular case of current signal was necessary windowing that signal with the intention to eliminate the transient pulse generated by the sudden increment of stator current at motor start-up. The window function elected was Hamming defined by:

$$
w(n)=0.54-0.46 \cos \left(2 \pi \frac{n}{N}\right) \quad 0 \leq n \leq N
$$

From the figure above, the values extracted are: 1. maximum peak of pulse generated by the difference between normal speed and fail speed; 2 . absolute time of speed maximum peak; 3 . wide speed pulse at $70 \%$; 4 . maximum peak of pulse generated by the difference between normal current an fail current; 5. absolute time of current maximum peak; 6 . wide current pulse at $70 \%$. These six characteristics were elected because of the behavior reported in Fig. 4, where the direction and magnitude of each curve inform the fail type and its intensity. Since this window is applied to all current signals has no important effect on the construction of patters.
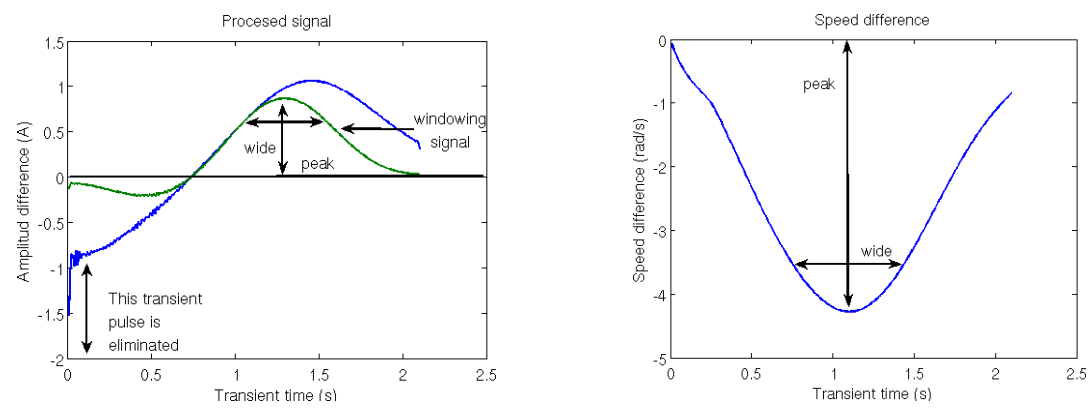

Fig. 5. Absolute patterns creation for current and speed

\subsubsection{Relative Bi-dimensional Patterns (Characteristics)}

Because exist a direct relationship between speed and current that can advise us about potential fail, the startup transient provides important information for diagnosis

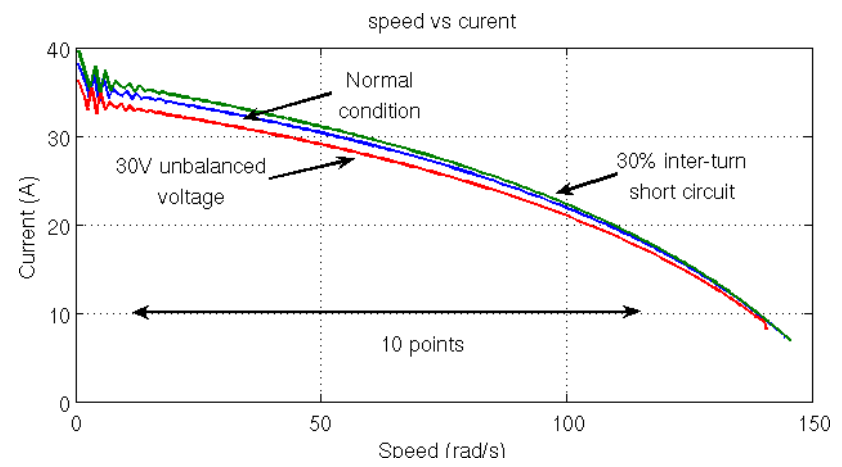

Fig. 6. Transient startup of speed versus current for different operations conditions 
purposes then, five points of transient speed and five points of transient current are added, then a totally of 16 points are created for a particular pattern. These ten last points are normalized to normal operation, that is, the speed and current values obtained is divided by normal operation obtained at same time, thus, for normal operation these ten points will have value of one, for abnormal conditions, these points will have values greater than or less than one depending on which type of fail. The Fig. 6 shows the transient startup of speed versus current with three possible operation conditions.

\section{Artificial Neural Network}

The artificial neural network chosen to recognize patterns has 16 inputs neurons, one neuron for each value described in above section. The output layer has 9 neurons, corresponding to eighth possible abnormal conditions and one for normal condition. Each output neuron is activated with " 1 " when recognize its own condition. After several test, the neural network was successful with two hidden layers, the first one with 13 neurons and second with 11 . The activation functions are "logsig" for both hidden layers, and output layer use a "purelin" function. The training performance was successful with an error of 1e-3 in 223726 epochs. The Fig. 7 shows the neural network topology.

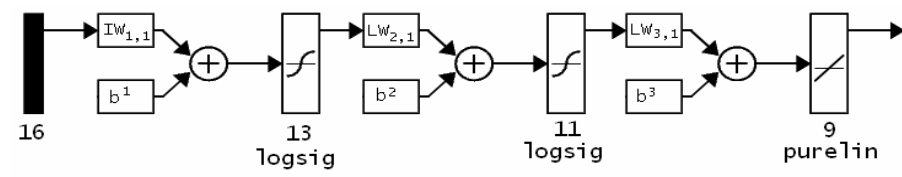

Fig. 7. Neural network topology and training performance

\section{Analysis of Results}

The neural network was tested with thirty motors, ten of them are real motors and another twenty were simulated. Five real motors present a know case of short circuit at stator winding and another were treated with unbalanced voltage. The twenty simulated motors present a range of inter-turn short circuit and unbalanced voltage. The results are shown in Table 1.

Table 1. Certainty of recognized motors

\begin{tabular}{|l|c|c|c|c|}
\hline $\begin{array}{c}\text { Motor } \\
\text { Type }\end{array}$ & $\begin{array}{c}\text { Motors with } \\
\text { inter-turn } \\
\text { short circuit }\end{array}$ & $\begin{array}{c}\text { Motor with } \\
\text { unbalanced }\end{array}$ & $\begin{array}{c}\text { Inter-turn } \\
\text { accuracy } \\
(\boldsymbol{\%})\end{array}$ & $\begin{array}{c}\text { Unbalanced } \\
\text { accuracy } \\
(\%)\end{array}$ \\
\hline Real & 5 & 5 & 85 & 90 \\
\hline Simulated & 10 & 10 & 100 & 97 \\
\hline
\end{tabular}




\subsection{Comparison with Others Research}

In [5], inter-turn short circuit diagnosis is developing by winding-function-based method analyzing stator current spectra; only a rise in some of the frequency components which already exist in the line current spectra of healthy motors can be observed, while [9] describes the use of Extended Park's Vector Approach of stator winding faults by identification of spectral components. In both previous articles, the authors create a own mathematical model, as occur is this paper, but both research make use of spectral analysis, a difference with this article, that suggests another paradigm to detect and diagnose inter-turn short circuit, based principally in the creation of patterns that linking the close relationship between speed and current at transient startup. In addition, this methodology is not tied a specific motor because the calculation method to obtain motor parameters is through data catalogue, therefore, it can be applied to a wider range of induction motors regardless of power, pole numbers or another characteristic.

\section{Conclusions and Future Work}

The presented work tested successfully a methodology to create inter-turn short circuit and unbalanced voltage patterns, it has established absolute time and bidimensional patterns that permits integrate all motor information as a system, and makes a diagnostic with a certainty $7-10 \%$ greater than close research. The essential concept is based that a minimum inter-turn short circuit and unbalanced input voltage produces a slight variation that can be identified confronting speed and current signal. For his purposes, a mathematical model with an associated computational algorithm was created with the aim of incorporating iron losses and more realistic rotor resistance behavior. The elimination of higher harmonics produces soft patterns that are eligible for neural network recognition. This research test the feasibility to identify early potential fails at induction motors. The next tests will include a wide range of motors and inclusion of another electrical fails like broken rotor bars into mathematical model and computational algorithm.

\section{References}

1. Altug, S., Chow, M.-Y., Trussell, H.J.: Fuzzy Inference System Implemented on Neural Architectures for Motor Fault Detection and Diagnosis. IEEE Transactions on Industrial Electronics 46, 1069-1078 (1999)

2. Chow, M.Y.: Methodologies of Using Neural Networks and Fuzzy Logic Technologies for Motor Incipient Faults Detection. World Scientific, Singapore (1997)

3. Ozpeneci, B., Tolbert, L.M.: Simulink Implementation of Induction Machine Model - A Modular Approach. In: IEEE International Electric Machine and Drives Conference, IEMDC 2003, vol. 2, pp. 728-734 (2003)

4. Costa, A., Galan, N., Ciumbulea, G., López, X.: Parámetros del motor de inducción a partir de datos de catálogo. Energía y Computación (2004)

5. Joksimovic, G.M., Penman, J.: The detection of inter-turn short circuits in the stator windings of operating motors. IEEE Transactions on Industrial Electronics 47, 1078-1084 (2000) 
6. Krause, P.C.: Analysis of Electric Machinery and Drive Systems. IEEE Press, New York (2002)

7. Liang, B., Payne, B., Ball, A., Iwnicki, S.: Simulation and fault detection of three-phase induction motors. Mathematics and Computers in Simulation 61, 1-15 (2002)

8. Arthur, N., Penman, J.: Induction Machine Condition Monitoring with Higher Order Spectra. IEEE Transactions on Industrial Electronics 47, 1031-1041 (2000)

9. Cruz Sergio, M.A., Marques Cardoso, J.: Stator Winding Fault Diagnosis in Three-phase Synchronous and Asynchronous Motors, by the Extended Park's Vector Approach. IEEE Transactions on Industry Applications 37, 1227-1233 (2001) 